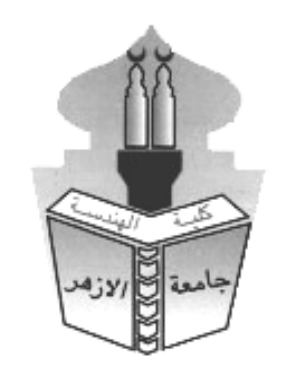

\title{
VALIDITY OF SOME SHEAR STRENGTH FORMULAE FOR PRE- STRESSED CONCRETE DEEP BEAMS
}

\author{
H. El-Esnawi \\ Civil Engineering Dept., Faculty of Engineering, Al-Azhar University, Cairo, Egypt
}

\begin{abstract}
In this paper, the validity of some published shear strength formulae were examined against test results. Data of 56 pre-stressed deep beams were used to evaluate the accuracy of these formulae. Tested models included S. Teng et al. model, Tan and Mansur model, and K.H.Tan et al. as well as Guo-Lin et al. modified strut and tie model. The assessment of these models indicated some models to be conservative while other overestimated the shear capacity of the tested beams. The model developed by Guo-Lin et al. was found to be in a good agreement with test results.
\end{abstract}

Keywords: deep beams; design methods; pre-stressed concrete; shear strength.

1. INTRODUCTION

Concrete deep beams are those having clear span to overall depth ratio not exceeding four, or concentrated loads acts within a distance equals double the overall depth from face of support as defined in most popular codes [1]. The assumptions used to derive the sectional theory are not suitable for deep beam. In engineering practice, deep beams encountered when designing transfer girders, pile-cap foundations, shear walls, off-shores and corbels [2]. There is no agreement found between researchers on an integrated approach to either model the shear behavior or determine the shear strength of pre-stressed reinforced concrete deep beams [2-7]. The aim of this paper is to investigate the accuracy of some shear strength models by examining them against different experimental test results.

\subsection{Current Design Methods of shear strength for deep beams}

In this section, some of the existing shear strength models for deep beams are reviewed. Some of these models are simple equations that represent the shear strength of deep beams in terms of nominal concrete shear strength; other models adopt more sophisticated methods such as the strut and tie approach.

\subsubsection{S.Teng et al. model}

S.Teng et al. [10] proposed an equation for shear strength of pre-stressed deep beams. This equation is an extension of an original equation from CIRIA Guide 2 [9]. The original equation of CIRIA Guide 2 is as follows.

$$
V_{u}=C_{1}\left(1-0.35 \frac{x_{e}}{h}\right) f_{t} b \boldsymbol{h}+C_{\mathbf{2}} \sum \frac{A y}{h} \sin ^{2} \alpha
$$

Where C1 is 1.4 and 1.0 for normal and lightweight concrete, respectively, C2 is 300 Mpa for deformed bars and $130 \mathrm{Mpa}$ for plain rounded bars. $\mathrm{b}$ and $\mathrm{h}$ are the width and depth of beam, respectively, A is the typical bar area intersecting the diagonal shear crack as shown in figure 1, and $\mathrm{f}_{\mathrm{t}}$ is the tensile splitting strength of the concrete usually $\left(f_{t}=0.4 \sqrt{f_{c u}}\right.$ to $\left.0.5 \sqrt{f_{c u}}\right)$. 
S.Teng et al. $[6,10]$ modified the previous equation to take into account the effect of the prestressing, if any, by taking the value of concrete tensile strength $f_{t}$ as follows.

$$
f_{t}=0.4 \sqrt{f_{c u}}+\frac{P_{e} \sin \theta \sin \phi}{b \boldsymbol{h}}
$$

Where $P_{e} \sin \theta$ is the effective pre-stressing force in the direction of the dotted line as shown in figure 2 .

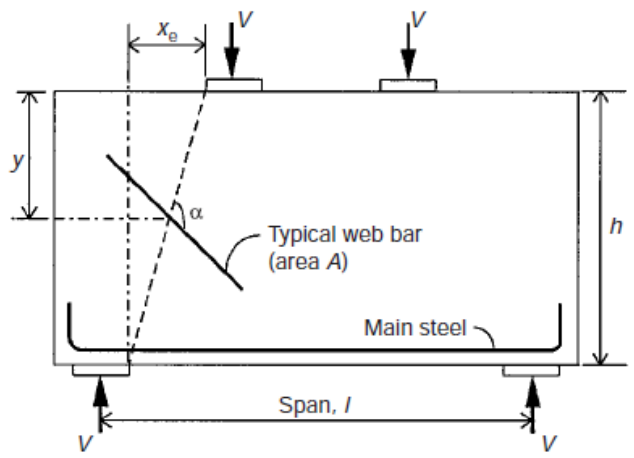

Figure 1. Typical bar area crossing the shear crack in CIRIA Guide 2 model.

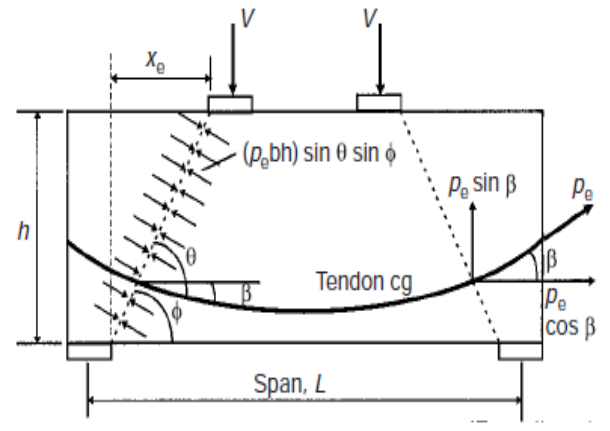

Figure 2. Idealization of the pre-stressing force acting on the shear crack in S.Teng model.

\subsubsection{Tan and Mansur model}

Tan and Mansur model utilizes a simplified strut and tie approach to calculate the ultimate shear strength of ordinary and pre-stressed deep beams as shown in figure 3 . The ultimate shear strength $V_{u}$ is given by the minimum value of the following equations [2]:

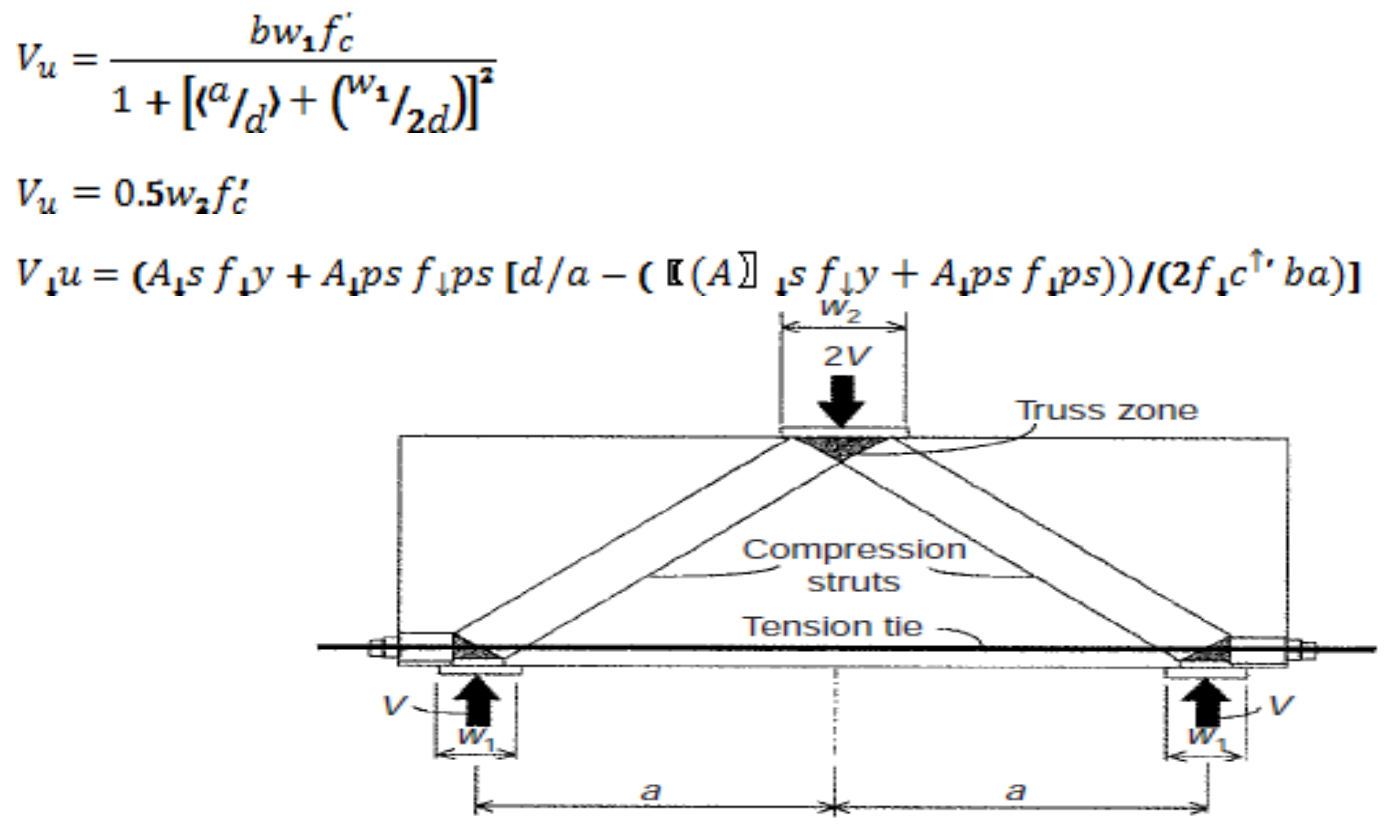

Figure. 3 Tan and Mansur truss model 
Equations 3 and 4 determine the ultimate capacity of the bottom and top nodal zones, respectively. Tan and Mansur model [2] assumes the axial strength of the diagonal strut is governed by these nodal zones. In addition, equation 5 determines the tensile capacity of the tie and accounts for both ordinary and pre-stressing reinforcement.

\subsubsection{K.H.Tan et al. Direct Strut and Tie Model}

Using strut and tie approach, K.H.Tan et al. [11] developed a simple and direct model for shear strength of pre-stressed deep beams. According to this model, the shear strength of pre-stressed deep beams is the minimum value of the following two equations:

$V_{n} \leq A_{s t r} f_{c}^{*} \sin \theta_{s}$

$$
V_{n}=\frac{1+\frac{2 F_{p e} \sin \left(\theta_{s}+\theta_{p}\right)}{\frac{f_{t} A_{c}}{\sin \theta_{s}}} * \frac{d_{p}}{d}}{\frac{\sin 2 \theta_{s}}{f_{t} A_{c}}+\frac{1}{f_{c} A_{s t r} \sin \theta_{\Xi}}}
$$

K.H.Tan et al. [11] model is based on the stability of the lower node. For the case of a lower node subjected to biaxial compression-tension stress state, equation 6 will govern the beam shear capacity figure 4. Nevertheless, in case of a lower node subjected to biaxial compressioncompression stress state, equation 7 is the governing equation. In this model, the amount of ordinary reinforcement, pre-stressing reinforcement, and web reinforcement contribute to the concrete tensile strength $\left(f_{t}\right)$ as follows:

$f_{t}=\frac{2 A_{s} f_{y} \sin \theta_{s}}{\frac{A_{C}}{\sin \theta_{s}}}+\frac{2 A_{w} f_{y w} \sin \left(\theta_{s}+\theta_{w}\right)}{\frac{A_{C}}{\sin \theta_{s}}} \frac{d_{w}}{d}+\frac{2\left(F_{p u}-F_{p e}\right) * \sin \left(\theta_{s}+\theta_{p}\right)}{\frac{A_{C}}{\sin \theta_{s}}} * \frac{d_{p}}{d}+f_{c t}$

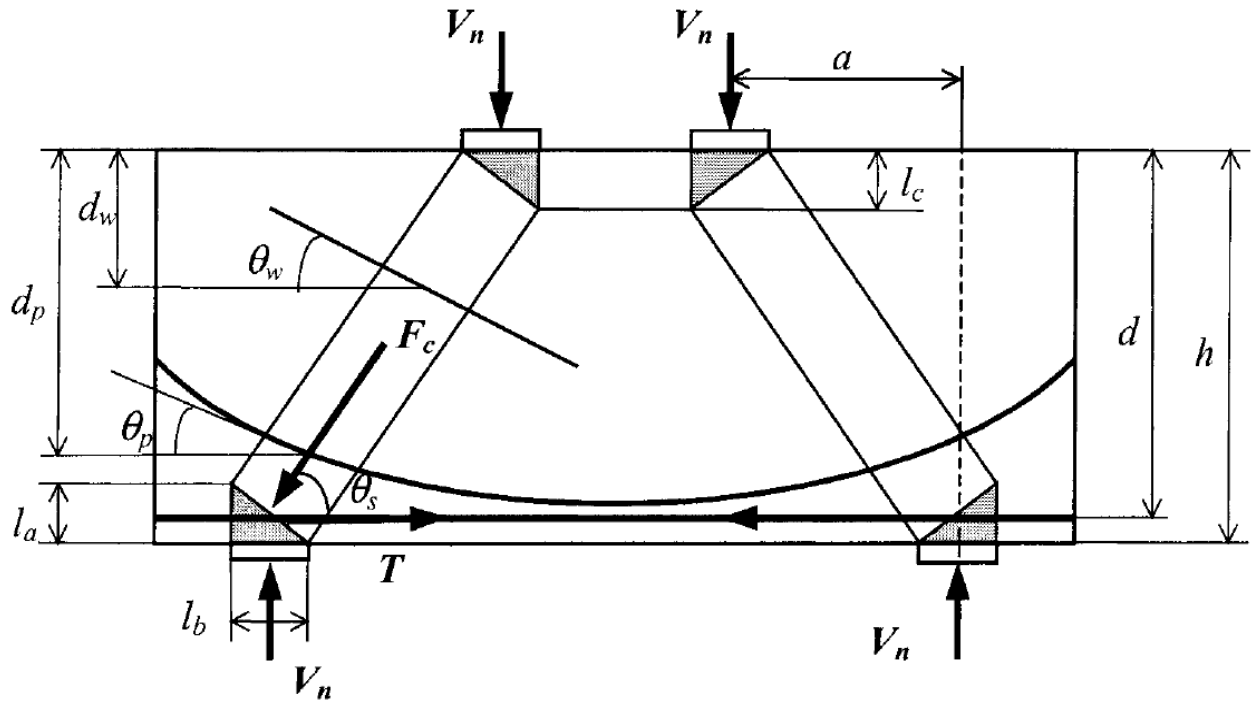

Figure. 4 K.H.Tan et al. Strut and Tie Model

\subsubsection{Guo-Lin et al. Modified Strut and Tie Model}

Guo-Lin developed a modified strut and tie model (MSTM) for the shear strength of pre-stressed deep beams [5] as shown in figure 5. In Guo-Lin model, the effect of pre-stressing is represented by equivalent external loads build in the model. In addition, the Kupfer-Gerstle tension compression criterion is adopted to account for concrete softening effect. The MSTM is given in following equations: 


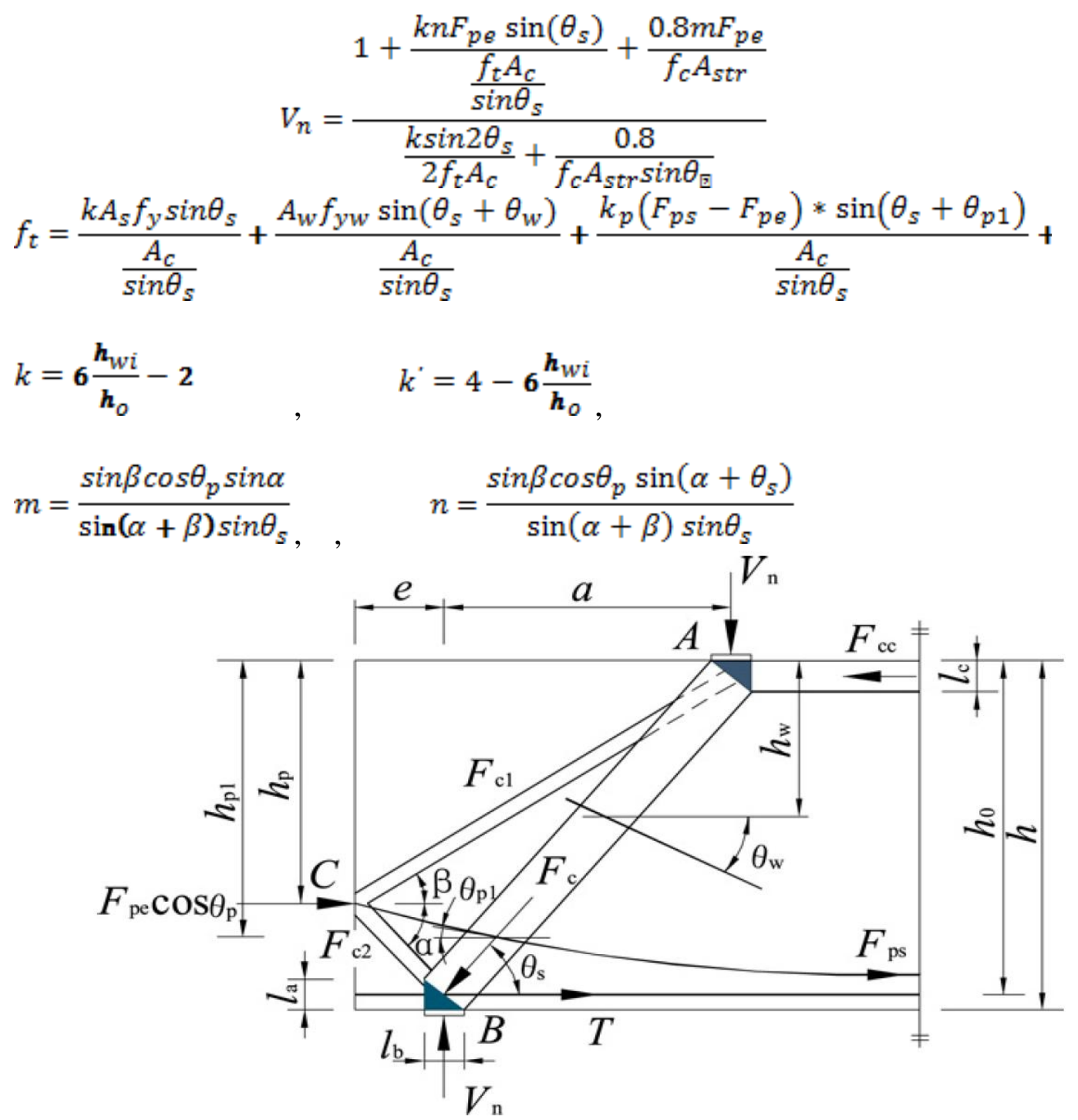

Figure. 5 GUO-LIN et al. MSTM

\section{THE ACCURACY OF SOME CURRENT SHEAR STRENGTH EQUATIONS FOR PRE-STRESSED DEEP BEAMS}

In the following sections, the validity of the pre-stressed deep beams shear strength formulae presented in section 2 is evaluated. The evaluation of these formulae is conducted by comparing the experimental results of most available studies ( including test results done and published by the author) versus the up mentioned models predictions.

Table 1-listed 56 simply supported pre-stressed deep beams collected from the literature; they had a compressive cylinder strength varying from $30 \mathrm{MPa}$ to $75 \mathrm{MPa}$, an overall height varying from $300 \mathrm{~mm}$ to $1750 \mathrm{~mm}$, and shear span to depth ratio from 0.55 to 2.35 . The horizontal and vertical web reinforcement varied from $0 \%$ to $0.73 \%$ and $0 \%$ to $0.58 \%$, respectively. These beams also had both rectangular and I-shaped cross-section, besides different tendons profiles and variable degree of pre-stressing. The label of each test sample is listed in the table as mentioned in its original reference where it can be reviewed. Plots for all four examined models showing values of shear strength from experimental results versus those predicted from the formulae are shown in figure 6. 
VALIDITY OF SOME SHEAR STRENGTH FORMULAE FOR PRE-STRESSED CONCRETE DEEP BEAMS

\begin{tabular}{|c|c|c|c|c|c|c|}
\hline Guo-Lin et al [5] & PB1 & PB2 & PB3 & PB4 & & \\
\hline $\begin{array}{c}\text { Alshegeir \& Ramirez } \\
{[12]}\end{array}$ & $\mathrm{I}-4 \mathrm{~A}$ & II-1A & $\mathrm{I}-3 \mathrm{~A}$ & $\mathrm{I}-4 \mathrm{~A}$ & & \\
\hline \multirow{4}{*}{ Teng et al. [6] } & P-1a & P-1ba & $P-1 b(2)$ & $\mathrm{P}-2 \mathrm{a}$ & $\mathrm{P}-2 \mathrm{~b}$ & P-3a \\
\hline & $\mathrm{P}-3 \mathrm{~b}$ & P-1c & $\mathrm{P}-1 \mathrm{c}(2)$ & P-1d & $P-1 d(2)$ & P-1ea \\
\hline & $\mathrm{P}-1 \mathrm{e}(2)$ & $\mathrm{P}-2 \mathrm{e}$ & $\mathrm{P}-3 \mathrm{e}$ & $\begin{array}{c}\text { P1-1.5- } \\
\text { WO }\end{array}$ & $\begin{array}{c}\text { P1-1.5- } \\
\text { WV }\end{array}$ & $\begin{array}{c}\text { P1-1.5- } \\
\text { WVH }\end{array}$ \\
\hline & $\begin{array}{c}\text { P1-1.0- } \\
\text { WO }\end{array}$ & $\begin{array}{c}\text { P1-1.0- } \\
\text { WV }\end{array}$ & $\begin{array}{c}\text { P1-1.0- } \\
\text { WVH }\end{array}$ & & & \\
\hline \multirow[t]{2}{*}{ Tan et al. [4] } & $\begin{array}{c}1 \mathrm{P}- \\
500 / 0.5\end{array}$ & $\begin{array}{c}\text { 1P- } \\
500 / 0.75\end{array}$ & $\begin{array}{c}1 \mathrm{P}- \\
500 / 1.0\end{array}$ & $\begin{array}{c}2 \mathrm{P}- \\
1000 / 0.5\end{array}$ & $\begin{array}{c}2 \mathrm{P}- \\
1000 / 0.75\end{array}$ & $\begin{array}{c}2 \mathrm{P}- \\
1000 / 1.0\end{array}$ \\
\hline & $\begin{array}{c}3 \mathrm{P}- \\
1400 / 0.5\end{array}$ & $\begin{array}{c}3 \mathrm{P}- \\
1400 / 0.75\end{array}$ & $\begin{array}{c}3 \mathrm{P}- \\
1400 / 1.0\end{array}$ & $\begin{array}{c}4 \mathrm{P}- \\
1750 / 0.5 \mathrm{a}\end{array}$ & $\begin{array}{c}4 \mathrm{P}- \\
1750 / 0.75 \\
\end{array}$ & $\begin{array}{c}4 \mathrm{P}- \\
1750 / 1.0\end{array}$ \\
\hline Tan\&Tong [3] & G1 & $\mathrm{G} 2$ & G3 & G4 & G5 & G6 \\
\hline \multirow{2}{*}{$\begin{array}{c}\text { H. El-Esnawi et } \\
\text { al.[13] }\end{array}$} & G1B1 & G1B2 & GB1(a) & GB1(b) & G1B4 & G2B2 \\
\hline & G2B3 & G2B4 & G3B1 & G3B2 & G3B3 & \\
\hline
\end{tabular}

\subsection{S.Teng et al. model predictions}

S.Teng et al. model [10] provided the underestimated predictions against experimental test results with closely scattered predictions. The mean value of $\left(V_{\text {pred. }} / V_{\text {exp. }}\right)$ was 0.810 , and the standard deviation was 0.206 . According to S.Teng et al. model, the concrete tensile strength $f_{t}$ is enhanced by the contribution of the effective pre-stressing force $P_{e} \sin \theta \sin \phi$

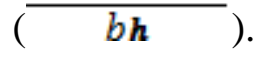

\subsection{Tan and Mansur model predictions}

Tan and Mansur model [2] predictions were relatively conservative with closely scattered predictions. The mean value of $\left(V_{\text {pred. }} / V_{\text {exp. }}\right)$ was 0.646 , and the standard deviation was 0.140. In Tan and Mansur model, the effect of pre-stressing was taken into account as an increased tensile capacity of the tie by a value of $\left(A_{p s} \cdot f_{p s}\right)$. The effect of pre-stressing on enhancing the softening behavior of the compression strut was not taken into account. 
VALIDITY OF SOME SHEAR STRENGTH FORMULAE FOR PRE-STRESSED CONCRETE DEEP BEAMS
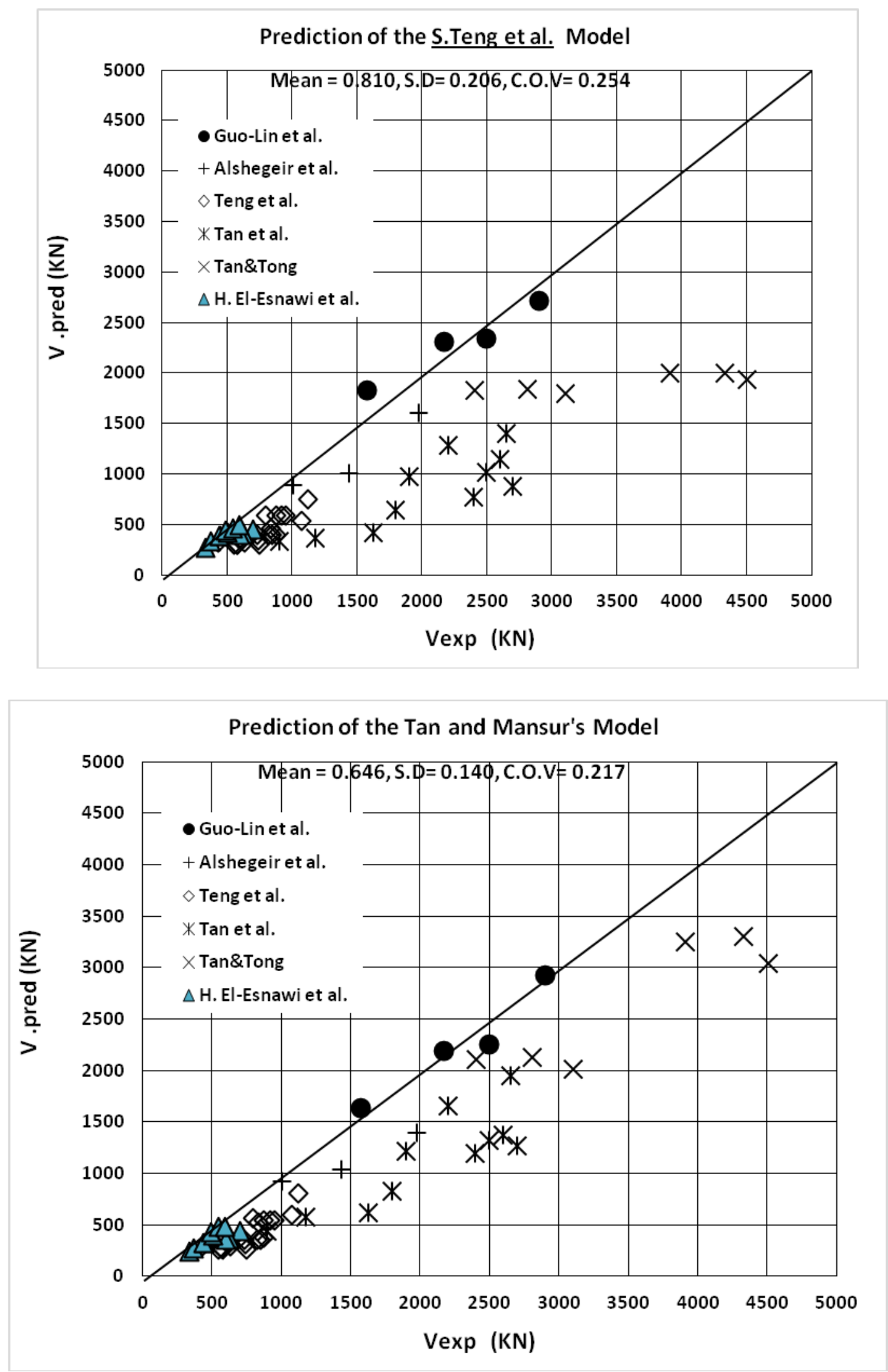
VALIDITY OF SOME SHEAR STRENGTH FORMULAE FOR PRE-STRESSED CONCRETE DEEP BEAMS
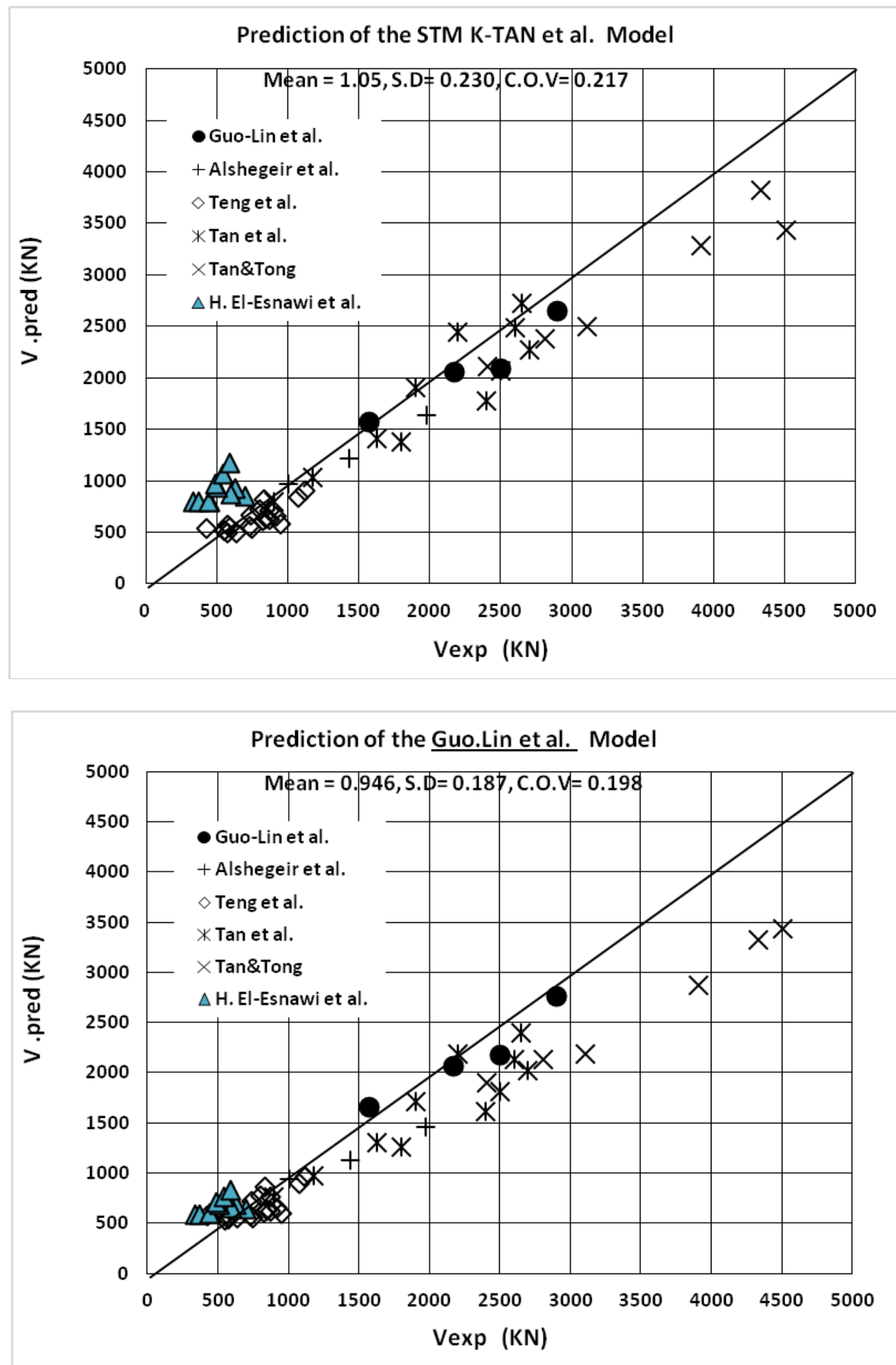

Figure 6 Predicted ultimate shear strength versus experimental results 


\subsection{K. Tan et al. model predictions}

K. Tan et al. model [11] closely overestimated the shear strength of most of the tested specimens with closely scattered predictions. The mean value of $\left(V_{\text {pred. }} / V_{\text {exp. }}\right)$ was 1.05 , and the standard deviation was 0.230 . However, K. Tan et al. [11] verified their model against several types of pre-stressed deep beams; the verification indicated their model to overestimate the shear capacity of beams without web reinforcement.

$\mathrm{K}$. Tan et al. model is based on the stability of the bottom nodal zone, which is subjected to either biaxial tension-compression stress state, or biaxial compression-compression stress state. For the case of biaxial tension -compression stress state, the concrete compressive strength is reduced due to the softening effect of the tensile stress. Therefore, K. Tan et al. proposed a linear interaction between the concrete tensile and compressive stresses based on the Mohr-Coulomb theory [14] as follows:

$$
\frac{f_{1}}{f_{t}}+\frac{f_{2}}{f_{c}^{\prime}}=\mathbf{1}
$$

Where $f_{1}$ and $f_{2}$ are the principal tensile and compressive stresses at the nodal zone respectively.

\subsection{Guo.Lin et al. MSTM predictions}

Guo.Lin et al. model [5] (MSTM) is the most accurate predictions for the shear strength. Corresar/ed to he tested specimens, it has the closest scattered predictions. The mean value of model is the most accurate can be regarded to the following:

- Guo.Lin et al. utilizes main and secondary struts carrying compressive forces.

- Guo.Lin et al. adopted Kupfer and Gerstle approach [15] for the linear interaction between the tensile and compressive stresses at the bottom nodal zone. In their approach

$$
\frac{f_{1}}{f_{t}}+\lambda \frac{f_{z}}{f_{c}^{\prime}}=1 \text {, where } \lambda=0.8 \text {. }
$$

\subsection{Conclusions}

- Tan and Mansur model predictions was relatively conservative with mean value of $\left(V_{\text {pred. }} / V_{\text {exp. }}\right)$ equals 0.646 , and the standard deviation was 0.140

- S.teng et al. model predictions were underestimated compared to the test results. Its mean value of $\left(V_{\text {pred. }} / V_{\text {exp. }}\right)$ was 0.810 , and the standard deviation was 0.206

- K. Tan et al. model (STM) closely overestimated the shear strength most of the test

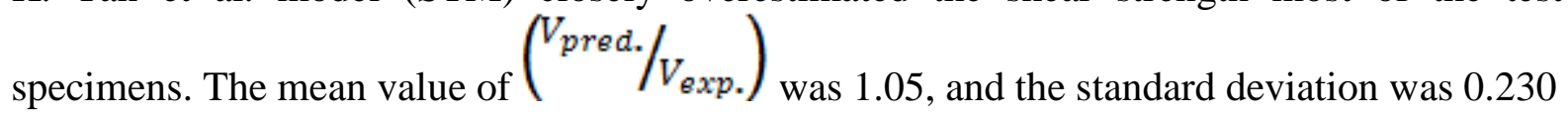

- Guo-Lin et al. model (MSTM) predictions were in good agreement with test results. The mean value of $\left(V_{\text {pred. }} / V_{\text {exp. }}\right)$ was 0.940 , and the standard deviation was 0.187 


\section{Notations}

a. Shear span of deep beam

A Area of typical bar crossing the diagonal shear crack

$A_{s} . A_{p s}$ Areas of unstressed and pre-stressed steel, respectively

b.d.h Width, overall depth and height of deep beam, respectively

$f_{c}^{\prime}$ Concrete cylinder strength

$f_{c u}$ Concrete cube strength

$f_{p s}$ Stress in prestressing steel when the beam fails

$f_{p e}$ effective Stress in pre-stressing steel

$f_{p y}$ yield Strength of 7 wire strand

$f_{t}$ Tensile splitting strength of concrete

$\left.\mathbb{Q}(l]_{0_{-}} L_{n}\right) \cdot x_{\square}$ Clear span and clear shear span, respectively

$M_{U} \cdot V_{U}$ Ultimate moment and shear force at the critical section

$S_{V} \cdot S_{h}$ Spacing of vertical and horizontal web reinforcements

$y . \alpha$ Depth and angle of intersection between steel bar and the diagonal crack

$W_{1} \cdot W_{2}$ Widths of bearing plates at reaction and loading points

$\beta$ Slope of draped tendon crossing a diagonal crack

$\rho$ Percentage of main steel, $A_{s} / \mathrm{bd}$

$A_{h}$ Area of horizontal web reinforcement

$A_{v}$ Area of vertical web reinforcement

$\rho_{\boldsymbol{h}} \cdot \rho_{v}$ Total horizontal and vertical steel ratios, respectively

$f_{y}$ Yield strength of web reinforcement or unstressed steel

$f_{y \boldsymbol{h}} \cdot f_{y v}$ Yield stresses of horizontal and vertical reinforcements

$\phi$ reduction factor for shear, material resistance factor or slope of a diagonal crack

$V_{u} \cdot V_{n}$ nominal shear strength

$V_{\text {pred. }} . V_{\text {exp. }}$ calculated nominal shear strength, measured ultimate shear strength, respectively

\section{REFERENCES}

1. ACI Committee 318, "Building Code Requirements for Structural Concrete (ACI 318M-14) and Commentary (ACI 318RM-14)," American Concrete Institute, Farmington Hills, MI, 2014, $151 \mathrm{pp}$.

2. TAN K. H. and MANSUR M. A. Partial pre-stressing in concrete corbels and deep beams. ACI Structural Journal, 1992, 89, 251-262.

3. K. H. Tan and K. Tong, Shear behavior and analysis of partially pre-stressed I-girders. The Structural Engineer Volume, December 1999, 77, pp.28-34.

4. Tan K. H., and Lu, H. Y., Size Effect in Large Pre-stressed Concrete Deep Beams, ACI Structural Journal, Nov-Dec. 1999, V. 96, No. 6, pp. 937-947.

5. Guo-Lin Wang, Shao-Ping Meng. Modified strut-and-tie model for pre-stressed concrete deep beams. Engineering Structures, 2008, 30, 3489-3496. 
6. TENG S., KONG F. K. and POH S. P. Shear strength of reinforced and pre-stressed concrete deep beams. Part II: the supporting evidence. Structures and Buildings, 1998, 128, No. 2, 124143.

7. Stephan J. Foster and R. lan Gillbert, Experimental studies on high strength concrete deep beams, ACI STRUCTRAL JOURNAL, Vol.95, No.4, 1998. Pp.382-390.

8. COMITE' EURO-INTERNATIONAL DU BE' TON/FE' DE'RATION INTERNATIONALE DE LA PRE'CONTRAINTE. CEB-FIP Model Code 2010. Cement and Concrete Association, London.

9. CONSTRUCTION INDUSTRY RESEARCH AND INFORMATION

ASSOCIATION.

The Design of Deep Beams in Reinforced Concrete. Ove Arup and Partners, CIRIA, London, 1977 (reprinted 1984), CIRIA Guide 2.

10. TENG S., KONG F. K. and POH S. P. Shear strength of reinforced and pre-stressed concrete deep beams. Part 1: current design methods and a proposed equation. Structures and Buildings, 1998, 128, No. 2, 112-123.

11. Tan KH, Tong K, Tang CY. Direct strut-and-tie model for pre-stressed deep beams. ASCE J Struct. Eng. 2001; 127(9):1076_84.

12. Alshegeir A, Ramirez JA. Strut-tie approach of pretensioned deep beam. ACI Struct J 1992; 89(3):296_304.

13. H. El-Esnawi, A. Hafiz and M. A. Eita. Experimental Investigation on Shear Strength of Unbonded Post-tensioned Concrete Deep Beams. Life Science Journal 2018; 15(3):11-17.

14. Cook, R. D., and Young, W. C. (1985). Advanced mechanics of materials, Macmillan, New York.

15. Kupfer H, Gerstle KH. Behavior of concrete under biaxial stress. Proc ASCE J Eng. Mech Div 1973; 1999(EM4):853_66. 